\title{
Mzabite Heritage in Southern Algeria: What Bioclimatic Lessons can Be Learned to Optimize Thermal Comfort?
}

\author{
Amina Bensayah ${ }^{1}$, Hamida Bencheikh $^{2}$ and Amina Abdessemed ${ }^{1}$ \\ ${ }^{1}$ LabETAP, Architecture and urbanism institute, University of SaadDahleb ,Algeria \\ ${ }^{2}$ LabGC, Department of Architecture, University of AmmarTelidji,Algerai
}

\begin{abstract}
It is urgent to act currently on the problems of overconsumption of energy as well as the environment and the economy. Energy is a direct mechanical source of many devices of an artificial thermal environment of the modern habitat. To cope with the consequences of the exceed consumption of domestic use, architecture takes part by focusing on the old constructive and functional solutions. The researchers are interested even fascinated by ancient and vernacular architecture; its buildings are a masterpiece of urban planning in matters of environment. Our study has clearly chosen as an example The Mzab valley; a qualitative and retrospective analysis which aims to describe and classify all the solutions and traditional climate strategies developed by the Mzabites to produce a real thermal comfort and a residential heritage to fight against climatic solicitations. We have checked and observed in parallel if these strategies are convergent or divergent with the recommendations and the needs of the specific comfort in our case study and predetermined in this paper by the method of Givoni. This analysis has shown that Mzabite architecture symbolizes an ancient bioclimatic knowledge, Its strategies generate a perfect harmony between climate, habitat and occupant, they formed an inspiring reference and exemplary lessons available of the designers; by re-adapting these ancient solutions and techniques of our ancestors with a suitable manner to contemporary architecture, and contributing to the improvement of comfortable climate.
\end{abstract}

\section{Introduction}

The problem of energy is causing much concern about the high demand and massive energy consumption around the world including human urbanism. The building sector is particularly impacting, it is responsible for a consumption of $40 \%$ of global production in energy [1].Like many countries in the world, Algeria, a developing state, also has a high consumption in the material and particularly the energy produced from electricity and natural gas in the housing sector, according to the National Agency for Promotion and Rationalization of Energy Use (APREU) [2] the largest consumer sector at the national level.

The housing sector is a large market, with many consumers acquiring more energy in relation to the huge domestic electrical appliance equipment in Algerian homes, including heating and air-conditioning equipments that seem to consume up to $51 \%$ of the total energy [2] ; they are accentuated especially in regions with hot and arid climates. To highlight commodities deemed necessary to face with the rise in average temperatures of hot months; the population of the affected regions uses the means of the household appliance industry to provide equipment generating room-conditioning solutions and providing comfort. However, a misuse of the devices, in other words, an abusive recourse of the artificial cold was noted in several families. This is largely justified by the poor design of the building, which is ignorant of the Climatology knowledge. Obviously, the climate is one of the various major factors that greatly influence the design of the building and its effectiveness; several studies have shown that the climate-responsive building allows a pleasant atmosphere conditioning conducive to interior comfort [3] even a reduction in electricity bills and energy costs [4].Unfortunately, the architecture of our days is inclined in front of a very diverse clientele in taste, choice and lifestyle far from the ideas constraints related to the climate of the context. However, their vernacular equivalent, which most often defines the old ordinary building but determined, possesses a construction concept and a potential of know-how by adapting the building scheme to its geo-climatic and bioclimatic context; the occupants have always sought their need for thermal comfort, and as the availability of technological devices was rarely available [5], they found refuge in the climate itself by adapting with great ingenuity [6].

Indeed, the moderate use of energy and the prevention of the environment are probably associated with a system 
of a comfortable thermal environment in many buildings of the modern time by acting in favor of an ancient several studies especially in hottest environments by referring to the thermal performance of the old houses, the results have shown that these last ones offering a good human comfort that the one resulting in today's homes [7] thanks to its appropriate design to climate elements and the use of local materials and products. Singh.M.K [8] pointed out that we should not underestimate the established solutions in vernacular architecture of ancient societies, rather it requires a systematic and detailed scientific understanding [9]; by taking advantage of the best solutions and responses to provide desired comfort away from energy misuse and we acquire a green culture at the service of the environment. Our present study, well thought out, aims in the same reflection and is activated on a site located about $600 \mathrm{~km}$ from the capital of Algeria, the Mzab Valley, an ancient place of civilization of the desert whose hostile and arid climate, this site has been classified as a world heritage since 1982 by a decision of UNESCO thanks to its five ksur erected from the XIe century. The Mzab strongly inspires contemporary architecture in its quality of respecting the environment and its impressive construction measures; a return to the past aims to describe and list all solutions and secrets of the people of the Mzab Valley to implement a much appreciated thermal comfort and a residential heritage to fight against climatic stresses. Based on a qualitative approach was founded on the observation and deep and detailed analysis of almost all the vernacular techniques and solutions called in this article "Traditional strategies of climate adaptation". These are classified at different scales, namely, the urban, architectural and constructive scale, without forgetting the habits, mores and lifestyles of conscious users to the climate conditions of their city.

\section{Research methodology}

To well succeed the current work, we followed a methodological approach descriptive that articulates on two integrated steps.

First, it is a question of analyzing and predetermining the bioclimatic particularities of the town under the experiment via the method of Givoni in order to better place the relationship between the Mzabite architecture of our case study and its physical environment (climate), by putting the recommended strategies and attributes to answer in stable way to the needs of an interior comfort.

Second, we have described and classified almost all traditional and local strategies of climate adaptation, a skill developed by the Mzabites to grant the interior thermal comfort of their homes. In this intention, we have treated the urban dimension and the arrangement of the constructions from the macro scale (ksur and oasis) o the micro scale (locality) in relationship with the architectural spatial configuration and the system of construction used, without forgetting the habits, mores and lifestyles of users in relationship with their habitats so that they introduce their know-how by consciously acting with climatic conditions of their city. All things considered, allows us to note otherwise and in parallel if these strategies developed by our predecessors, are convergent or divergent with the architecture; this architecture is a field of experience of

recommendations and the needs of a current comfort announced in our bioclimatic analysis of Givoni and which we detail in the following section.

To support this specific study, we have used a qualitative analytical approach based on an observation in the field. In addition, we use scientific works that describe the traditional structures of the Mzab in order to gather more necessary and appropriate information with the subject of our work, a global attempt to understand the alternative between all information from our observation, and those acquired by our documentary research in order guide our study toward the objective indicated above.

\section{Bioclimaticanalysis:The Diagram of Givoni}

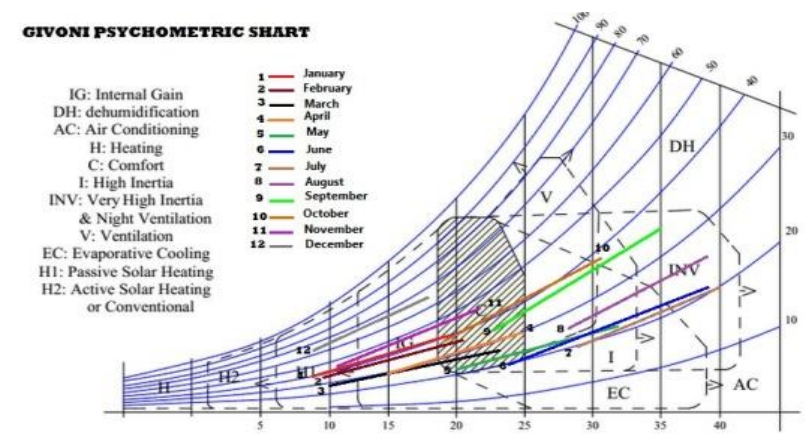

Figure 1.Bioclimatic diagram applied on the Mzab valley.

The interpretation of the above psychometric diagram of Givoni "figure 1" applied to the Mzab valley, gives us the means to glimpse the appropriate architectural solutions, chosen; and also a way of using the spaces to be closer to comfort all year long as follows:

The period from December to March, otherwise, the nights of the month of November and the month of April, it stands out as recommendations a passive solar heating and the internal heat gains in the interior of the houses. For this purpose, solar inputs should be maximized which constitute a major source of heat in the same way of those produced inside the locals.

During the months of June, July, August and September, night ventilation with high thermal inertia and evaporative cooling are recommended. It should also be noted that the end of August, and the months of September, October and May, a diurnalventilation seems necessary and useful during some moments of the day because the temperatures are lower.

\section{Traditional strategies of climate adaptation}

\subsection{Urban Scale}

\subsubsection{Ksur Compact settlements: configuration and Structure}




\subsubsection{Compactness of the urban fabric}

Ksur, plural of the word «ksar », coming from the Arabic language "qasr» which means palace, this word also indicates «agsir » of a Berberinterpretation according to Chérifi.B [10], this building designates a mountain slope opened on a set of housing [10], The ksur of Mzab are a gathered structures as a defensive figure, limited by high encircling walls of 4 to 5 meter to ensure a defense to the city and limited construction sites.

Indeed, ksur present a regular aspect. The mosque with its minaret in quadrangular pyramid, this place of worship occupies the summit; below, houses terraces which are arranged as they are already indicated figure above "Figure 2". Compactness usually followed during the establishment of housing, these are agglomerated to each other in order to reduce the number of external walls which constitute a source and place of exchange of heat and cold with the external environment. In summary, the principle dominating in the construction of Mzabite houses is having the minimum of walls in contact with the outside except the main facade.

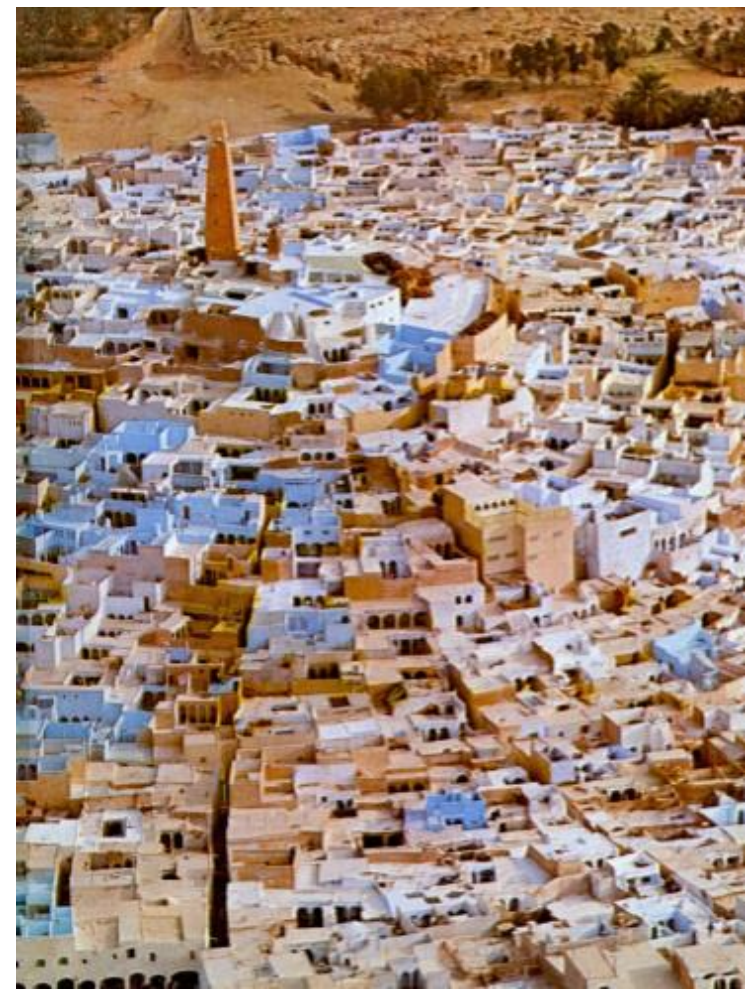

Figure2. Aerial view of "Ghardaia" Ksar of the Mzab valley shows the morphology of the tissue. [11]

\subsubsection{The Streets:means of protection against any rigor of the climate}

\subsection{StreetsSchema:sinuous and deep}

The traffic within the ksar occurs in a deep and winding streets with a prospect ( report $\mathrm{H} / \mathrm{L}$ ) often superior or equal to 1 .These streets are accessible only to pedestrians and animals (donkeys, mules) as means of transport of various merchandises.
These narrow streets are found in the high parties with a width between 2 to 3 meters in maximum [12]; and the widest ones are found in the lower part of the city .In this context Benyoucef. B highlighted that this architectural artwork leads us to believe to an urbanism which is very thoughtful and faithfully translated a strong desire to preserve the privacy, the security and the fight against such climatic conditions [12] in the use of streets whose role of narrowness, the depth and the winding layout is to shade the outdoor spaces (streets) and constructions via a shared shadow between facades in summer ; and also to be protected against the cold and violent winds during the long winter nights. Work carried out in some ksur of the Mzab valley, citing Beni-isguen, draw a profile of the outdoor comfort, this work has shown that the strength and the intensity of the heat are much high in the cleared sites than at urban traditional sites which are studied (ksur) [13] whose configuration is compact with narrow paths.

\subsection{The Covered passages «sabat »}

The street profile reported above, reduced so the maximum the sun rays and the duration of the sunshine with shadow oriented according to the street and will last for a longer time at the day; in the opposite case, where the duration of the shadow is too small, a thermal protection at the streets level is desirable. Some «Sabat» or covered passages the shadow and the freshness to the pedestrians of the cities and to the surfaces of the facades below. We find an elongation of the upstairs of the adjoining houses depends on the small street which doesn't need to be wide at this height and who is thus shaded. See "figure 3" here- after.

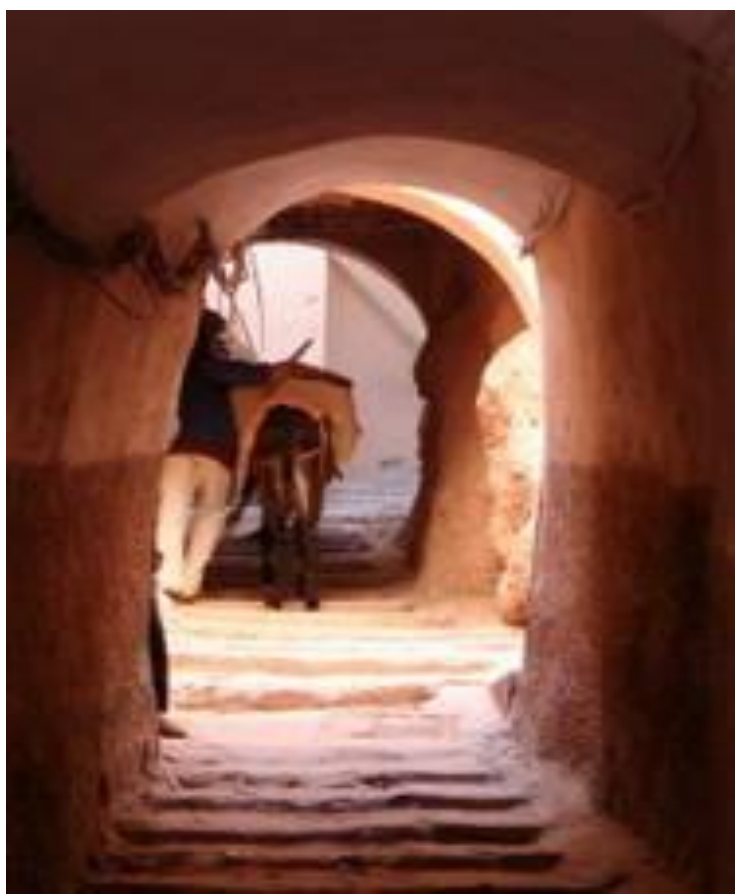

Figure 3.Covered passage with curved rhythm bringing shade (Asabat). [14]

Kitous.S and $\mathrm{Al}$ [15], demonstrated that the covered passage in the ksar of Ghardaïa has a considerable influence on the acceleration of the air. This aerated increase occurs 
even in the conditions of weak wind $(0.5 \mathrm{~ms}-1)$ and contributes in a strong ventilation of the street and its dwellings [15].Otherwise, we find a streets equipped of arcade gallery make solar radiation less severe and offer a shadow, for example the streets of commerce which extends the market (the souk).

\subsubsection{Height defined by the right to sunshine}

Everywhere in the ksur, houses submit to legal measures in laws, principles and even in manners of construction, adapting the ORF - law of urbanism and of construction established by the Mzabites - inspired of the holy book «Coran ». This law determines the common and particular servitudes of the inhabitants for a good management of the common relationship, and of the neighborhood. In this context, we emphasize as an example, the height of houses where it is strongly not allowed to differ and to go beyond of 7 meters in the ksar; in the center, this height is reduced even a 6 meters as the houses already benefit of the natural declivity of the ground [16], we remark sometimes even the presence of ramps following steep reliefs . The height is defined as principle of right to the sunshine whose every dwelling must be able to enjoy and none should cover and darken the floor terrace of his neighbor. See "Figure4". This regulation allows to see clearly just the first worry of Mzabites was the modeling of their houses in front of the climatic and the topographic necessity of the site.
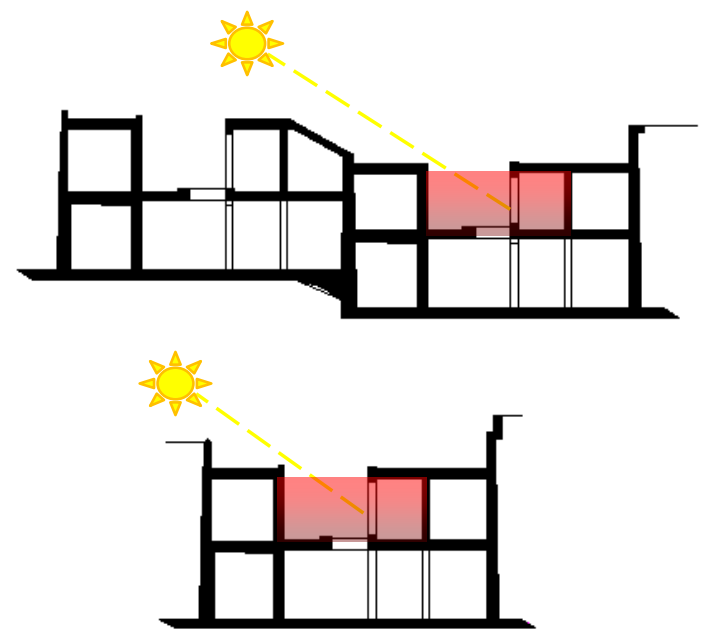

Figure 4.Adjoining buildings and sun penetration into space.

\subsubsection{Oasis of gardens and date palms}

\subsubsection{Vegetation and water}

At the foot of ksur and at the bottom of the valleys, we find there the Oasis considered often cities for the summer seasons. These places are closed and narrow with a greenery of private gardens where are planted high date palms source of life and shadow of homes dug in it See "Figure 5". These places are also the origin of a huge freshness more coveted by the inhabitants at time of overheating of the ksar.

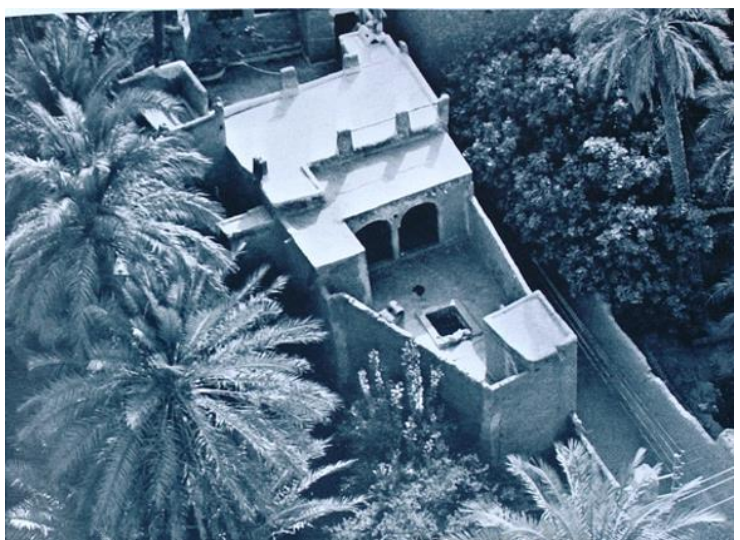

Figure 5.Summer house at Béni-Isguen palm grove. [14]

Really, the importance given to the vegetation and the water of artificial basins or of irrigation is a quick and essential asset. Vegetables and the evapotranspiration of the water will allow moisten the air and reducing the ambient temperature of this Oasis. Research has been done on the consequences of the flora in a hostile climate, results show that this vegetation is a major element to fight against the extreme heat of the summer and a way of cooling and refreshment from $2^{\circ} \mathrm{C}$ to $3^{\circ} \mathrm{C}$ [17] so a thermal improvement while reducing the costs advocated for air conditioning homes located in this environment bioclimatology subject.

If we come back to our Givoni bioclimatic analysis applied to the Mzab valley above, this strategy of evaporative cooling is recommended during times of the moments of overheating approach comfort; we see that the Mzabites of yesteryear produce this thanks to the oasis "the only vegetation" " and by the obligation to refresh and to not submit to any undesirable climatic conditions.

\subsection{Architectural scale}

\subsubsection{The highly compact form of the envelope}

Reduction of the envelope surfaces of construction implicitly involves a reduction of contact and exchange with the external environment. Assuredly in the mzab, the reduction of surface is not summarize vertically through adjoining systematically found during the elaboration of urban fabric as we have seen previously; likewise a reduction realized at the horizontal surfaces, a maximum density obviously acquired in Mzabite housing which seems in compact on itself with an area approximately $35 \mathrm{~m}^{2}$ to $100 \mathrm{~m}^{2}$ in maximum with a division of space in ground floor, floor and accessible terrace in accordance with a rectangular or square plan.

\subsubsection{Introversion and openings}

Mzabite houses are identical in all cities of Mzab.To counteract to the undesirable thermal consequences especially that overheated period, it is organized in close manner (introverted) with blind exterior frontages, except, the front door as a rectangular opening applied to the wall of the facade, and some openings are sometimes upstairs Ravereaux. A [14] points out that these openings are 
designed according to the need for light through small slits. See " Figure 9 ", these last are reduced $7 \mathrm{~cm}$ of measuring in width and height varies from $30 \mathrm{~cm}$ to $6 \mathrm{~cm}$ [see Reference 14, page 176], They are placed at the top of the space to protect intimacy, to ventilate space and to protected from the sun's rays. Indeed, Mzabite house matches with the type of house with covered courtyard called Amas n'tidar (this word literally means: the centre of house). This last one constitutes the vital and functional central space of the house around which is carried out the distribution of different pieces lacking of windows which gonna reduces the contact of these pieces with the outdoors .See "Figure 6"a little further.

\subsubsection{Enclosed courtyard (Amas n’tidar)}

\subsubsection{Typology: forms a device in response to the hostile climate}

Its typology is in response with the hostile meteorological conditions especially the extreme temperatures and the winds charged of dust and sand. In reality, the Mzabite house is a heritage of an identical pattern of Maghrebian houses and Mediterranean houses known of open courtyard. However, it was wisely adapted to the excess of the saharian light; it was narrowed and reduced in dimension and the courtyard is fully covered to let a moderate opening commonly called the "chebbek" in Arabic, it is a zenithal holes in rectangular from practiced in the center of the ceiling of the ground floor where the air and the light penetrate. See plans of a typical Mzab's dwelling on the picture below "Figure 6". (Architectural survey realized by the OPVM technical team [18]).

\subsubsection{Courtyard as a thermal regulator}

The patio contributes strongly to the regulation of the indoor thermal environment, as an example:

In summer, during the night, when the temperature of the interior of the house is higher than that of the outside, the "chebbek" is often open all night to allow the fresh air to settle at inside the house by evacuating overheating due to solar or internal gains, as shown in the picture below "Figure 7".The structure of the ground floor is also aerated and cooled during the night. During the day, the "chebbek" is covered with a wet mat or with palm branches interlaced to prevent the penetration of the solar rays and the scorching heat inside the house, thus improving the thermal environment.

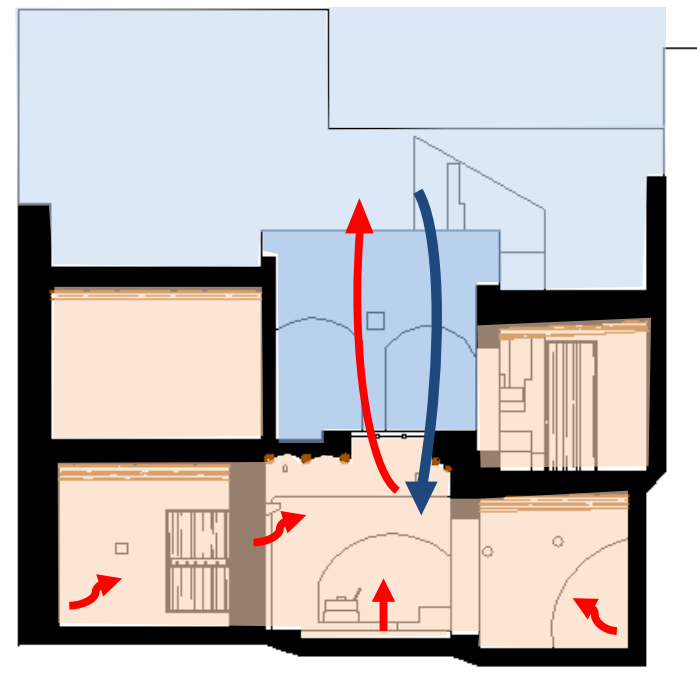

Figure 7.Verticalcross (AA) shows the role of the courtyard in the regulation of the thermal environmentinside the house in summer. Legend: $\square$ Warm $\square$ Cool $\square$ Cooler.

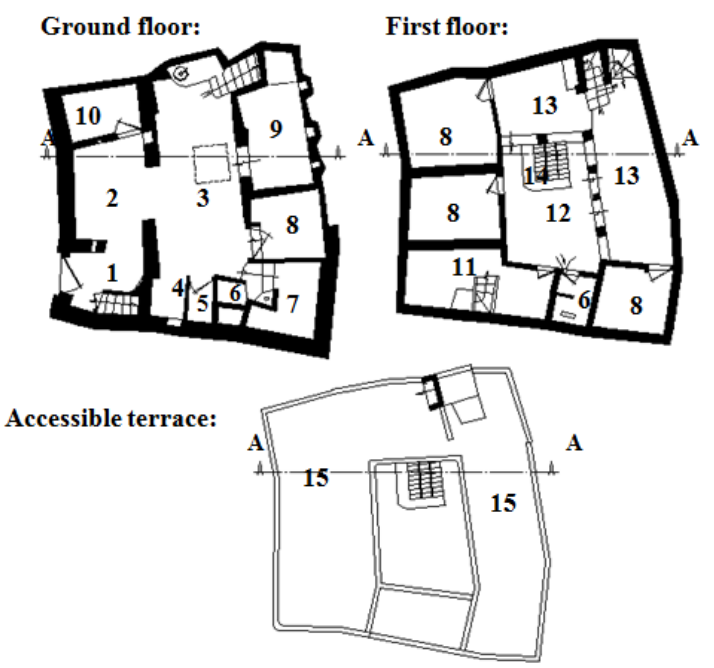

Figure 6. Architectural plans of a typical Mzabite house. Legend: 1. Entrance (Taskift); 2. Women space for weaving/ Space of transition (Douira);3.Courtyard (Amasn'tidar); 4.Kitchen corner; 5.Shower room.; 6.Latrine pit; 7.Storage room; 8.Bedroom (Tazka); 9.Women guest room /Family living room (Tiziferi); 10.Deposit local; 11.Reception room for men (Laali); 11.Open space (Tighargharet ) ;12. Gallery (Ikomar); 13.Zenithal opening of the courtyard (chebbek); 14.Terrace (Stah). 
In winter, the process of improvement and of comfort is different from that of summer: the "chebbek" is opened during the day to benefit from the solar rays bright and hot; and closed during the night to protect of cold.

Indeed, the chebbek of Courtyard appears as the only opening to the outside except the front door. These set of openings contributes enormously to aventilation mentioned below.

\subsubsection{Natural ventilation}

The natural ventilation -this feature- is well strong recommended. Natural ventilation will contribute an appreciated comfort during the seasons of the year "See bioclimatic analysis mentioned above ". A renewal of the air at the Mzabite house is assured and managed thanks to the applied openings: Chebbek of patio, door of entrance, small openings in the facades ....The air intake using the open front door of zigzag entrance "figure 8", while the zenithal of the patio " chebbek ", and even the stairs that give access to the floor allows a fresh air intake and an evacuation of the hot air less dense and higher.

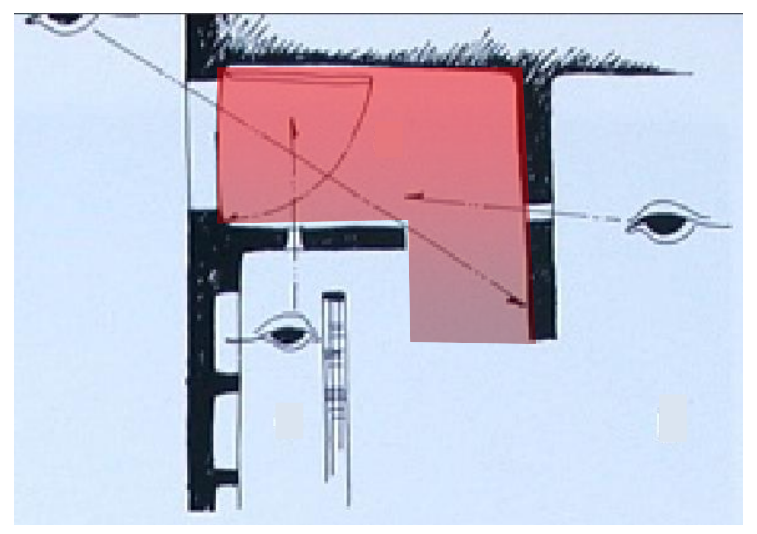

Figure8. Zigzag entrance (colored zone in red) :allows at the same time the intimacy of the inside of the houses and the opening of the door permanently, so that the air can penetrate and ventilate the internal space.

\subsubsection{Semi-open space / open space: Ikomar/ Tighargharet}

By studying the floor of the house and its structure in relation with the ground floor, we will find a feature of floor which is summarized in two parts: A part is semi-open, developed in one or two sides overflowing with arcades, called "lkomar" serving from different pieces of the floor, and opening on another part discovered named " Tighargharet ".This last one is found above the Amas n'tidar (the patio) guaranteeing the presence of the "chebbek" medium of ventilation and a passage of light to the ground floor as we had mentioned out before.

Indeed, all these areas offer a huge place of life and delight for the inhabitants for protect or enjoy the sunshine during the day. Ikomar presents a portico that covers nearly $30 \%$ of the total floor area. The figuration of lkomar and its direction usually oriented to the South-East gives the way to stay protected from the highly vertical solar rays in summer season and to enjoy a shading accalment; and in winter season, as the sun islow and less hot, an ambient and radiant heat fill this place -lkomar- from the first hours of the day," Figure 9".

When in the Tighargharet, this one is in effect a terrace surrounded by four walls of protection, also filled of solar rays well favorable the day after the freezing cold of winter nights.

According to our bioclimatic analysis of Givoni, the sun is a component of passive energy strongly recommended in winter to give better internal conditions of the habitat. Really, the consideration of the sun in architecture is a very ancient theme [19]; the Mzabites are witnesses of that. Their rules allow sunshine, like the defined height, he design of spaces exposed to the sun (open, semi - open), and the equitable orientation to all the houses of ksar, namely, the Ikomar (South-East oriented).

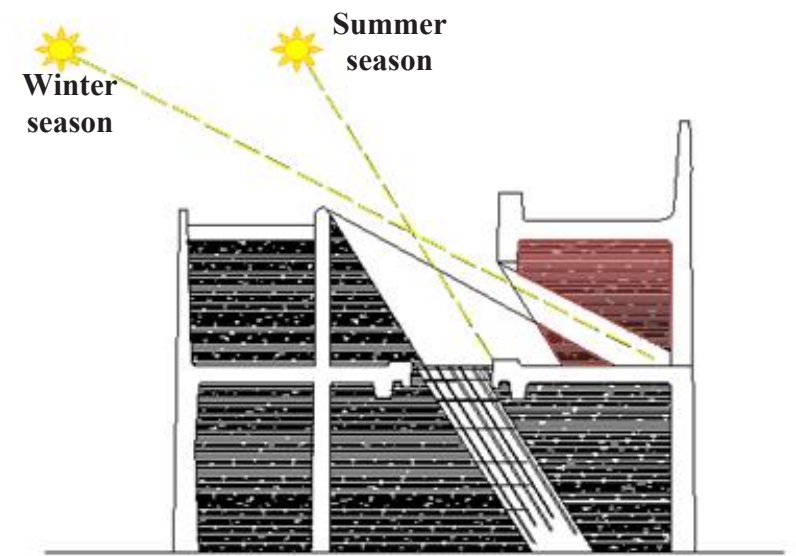

Figure 9.The penetration of sun inside the ikomar (colored zone in red).

\subsubsection{Underground space: The cellar}

Deliberate space of topographic and morphological principles of Ksar, the Mzabites have benefited from the nature of their site, some homes almost buried in the earth and possessing a basement. The rocky ground of the Mzab valley is suitable to a thermal quality of homes with cellars.

Underground structures are favorable space with advantageous properties such as a constant temperature [20] almost all the year thanks to the high thermal inertia of the ground [21]. In fact, these spaces are used essentially for the relaxation of the Mzabites; its independence from solar radiation provides a temperate atmosphere insummer is and even hot in the cold nights in winter.

\subsection{Constructive scale}

\subsubsection{Materials, techniques and processes of construction}

In addition to these approaches related to different strategies and methods of urban planning and architecture to provide hydrothermal comfort. The Mzabites occur otherwise an ingenuity and an intelligence about the construction of their houses, they have employed an own edification with unequal know-how to other ksur of Algerian south a 
building art befitting their entourage in a framework of economy and climatology. This construction technique could be interpreted according to the remark of Benyoucef. $B$ [22] in the use of materials extracted from the ground of the Mzab valley (limestone rock) which allows a better adaptability of the products: stones, sand, mortar, palm wood.....etc. This constructive material used in a manner that allow an ambient and suitable temperatures within the houses .This is what we are going expose in the coming sections.

\subsubsection{Thermal inertia of the envelope}

Thermal inertia of the envelope is an essential parameter for the amortization of the heat from the sun., In that respect maintain the comfort of housing. Mzabites got an ability to realize their desired comfort by constructing walls and roofs that are heavy and thick serve as a thermal flywheel: retaining the freshness in summer and the heat in winter.

\subsection{The walls}

The walls are formed of limestone's assembled with lime mortar or Timchent (traditional plaster). Mainly, the high thermal capacity of limestone allows to stabilize the ambient air of the Mzabites dwellings, according to previous studies carried on houses located in hot environment subjected to the same climatic characteristics than that of the Mzab valley. See reference [23].In effect, the walls in the Mzabite house are usually very thick, their thickness is one meter at the base progressively decreasing of $10 \mathrm{~cm}$ minimum at the terrace .This dimension allows to absorb and accumulate the maximum of excesses heat from the sun, to restore them later when the solar offers just missed [24] in general with the chebbek always opened from the inhabitants of the house during the summer nights when it is cold.

We note in this context that Mzabites had mastered a solution to approach the comfort, already seen and recommended after the interpretation of the Givoni diagram, it is the case of night ventilation linked to the thermal inertia, in other words, they realized this strategy formerly, first by the design of the components of their building, sort of, the thermal inertia .And second by the good use of the locales, as the night ventilation by opening chebbek and door in summer.

\subsection{Traditional ceilings}

The ceilings are realized in a flat way serving as roofs and floors because the external parts are an accessible terraces; which are vulnerable to heat and cold.

Floors are formed on the base either by tight lattice of palm ribs; or by flat stones; or by stone vaults linked with the timchent, arranged between the beams in trunks of palm spaced from 30 to 40 centimeters. Starting of such supporting structure, We find a layer of compact earth [22] or tamped sand [26]its thickness can reach 30 centimeters, It will serve as insulation and thermal mass combating climatic rigor of the external environment ; another layer of lime mortar of 4 centimeters is spread above.

\subsubsection{Constructive details of external surfaces}

\subsection{Rough texture of the facade}

The Mzabites realized a technique of rough and traditional coating applied with palm leaf got rid of its fruits, or manually with traces of plaster. This plastering rough and irregular limits an excess of warm up on the vertical. This plastering, is an assortment of sand and lime, it will bring strongly shadow to the bottom of the facade surfaces formed of various coarse reliefs "Figure 10". This rough and irregular plastering limits an excess of warm up on the vertical wall.

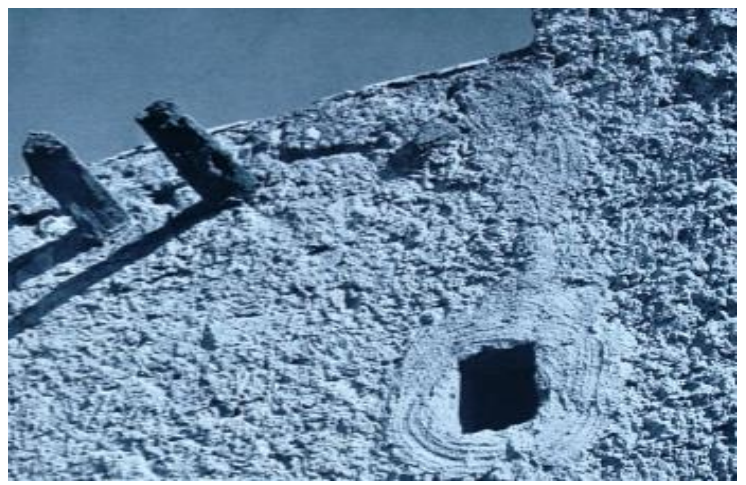

Figure10. Rough plastering/rendering of the facade [13, p73]

\subsection{Light colors of outer coating}

A significant part of the thermal exchange between the interior of the building and the external environment occurs through the facade and the roof of the courtyard that vertically receives a lot of direct solar rays around the midday.

In the warm zones, the application of light colors is eagerly exploited. In the Mzab valley, we notice the frequent use of milk of lime with a light color, especially, the white color cream and even light blue "Figure 2". This participates strongly in the reflection of the sun rays hovered above the surfaces and thus improving the thermal response of the walls, Since light colors correspond to an absorption factor noted $(\alpha)$ less than $(0.2)$; while plus the color is dark $(\alpha)$ approximate to (0.9) [25].

\subsection{Use, mores and way of occupation according to the climate}

The combination of various strategies listed on the urban and architectural scale previously arranged, allow us to seize at first that the microclimate of the zone where the habitat are built differs, affecting the indoor thermal environment of houses, according to whether it is a habitat of the ksar or that of oasis. And secondly, the spaces of habitat may have a different ambient temperatures which is different as long as they don't receive the same amount of solar rays, seen from the location of each space, pursuant it is closed (rooms around the courtyard), or open to the outside, Passing by a series of vast places from the patio, to the Ikomar (arcade portico) to the Tighirghert and terrace (the most open place). This plan encourages inhabitant to move during the day and 
night; in winter or summer, to the ksar and the oasis ; and between different places of the house, in search of conditions the most lenient . This is what we qualify the daily and seasonal nomadism .

In winter: The ground floor will have a constant attendance during the ends of the afternoon and the nights for the reason to be protected from the cold of winter, in the morning, the ground floor doesn't benefit enough of virtues of the sun by the chebbek as the rays are much horizontal See figure 8- The inhabitants move from the floor to the lkomar, its orientation to the south-East favorable in strong sunshine and also sheltered of prevailing winds of the south -west.

The Mzabites consider "Ikomar" a privileged place of living during the day by exercising many domesticactivities of the daily life such as the weaving, the drying of some foods or well enjoy the sun of the day and take their meal. Terraces exposed to the sun are also used as a place of stay for women stay, we valuing the importance of the doors in neighboring Mzabite homes as places of chatting and gossiping for women in a frame of relationships, communication, and good-neighbourliness. We can communicate in Mzabite society on the terraces, passing from the terraces of a house to the other and to stay to warm up and to drink a coffee, these places are diurnal location for women primary users.

Effectively, the morning is the most active period of the day in a traditional society among that the Mzabite community. The repeated displacement or local nomadism of the inhabitants of the house at this moment of the day in a semi-open space,open space ;to activate in domestic work and chores in this external smooth and lenient place shows that the Mzabites are conscious and lucid to the oblique radiation of the sun to take advantage of the comfort brought from the sun, formed a principle passive source of heat (see our bioclimatic analysis) in an old society that doesn't have knowledge in using the artificial heating.

In summer, the ground -floor space is used all day long to its comfort and its moderate and pleasant cold, a freshness produced and accumulate thanks to the combined effect of inertia and night ventilation. The inhabitants pass the major part of their day in the "Amas n'tadar" (courtyard) of the house where they take their meals, or in another place called "Tiziferi", a wide and open room on the Amas n'tidar [See house plans : " Figure 6 "] .For people who that have a cellar in their house, they take a nap,because the cellar is the most fresh and wet part of the house. The night, the inhabitants run away from the stifling and very hot Amas n'tidar of the rays accumulate in the thick walls the wholeday. The Occupants usually move to the terrace to enjoy the advantages of strong variations of temperature and sleeping in an open sky. The acroterion, this balustrade has enough compatible height to preserve the family intimacy.

It will be interesting to point out little bit fast than the rarity of furniture and the simplicity of the equipment that can be available in different parts of the Mzabite house allowing and facilitating these easy movements led by the concern for comfort; for example; the use of mats and pillows to sit and to sleep, the presence of fireplace, this conduit probably erect in floor helps in preparing meals in this part of the house during the summer far away from kitchen of the ground floor to avoid the overheat of cooking and culinary preparations, a real source of the internal heat which is strongly desired in winter where the meats are cooked in the ground floor unlike in summer.We confirm that the users of Mzabite houses have taken advantage in the old days from the heat gains emitted inside the local, that are recommended in winter according to our bioclimatic analysis of Givoni. Invoking this bioclimatic and architectural study, wondering about the ability of to moving and changing the places day and night in a traditional Mzabite house, however would it be an actual possibility in a modern house where the space is defined and tangible to the introduction of the present means of very sophisticated comfort and of furniture equipment ,formerly nonexistent , bed, closet ,table, chair, commode, mattress ,armchair and other appliances?

The way of living of the Mzabites that nature of their activities constraint them to move towards the oasis (summer stay) during the heat wave; some rich families had a second residence at the oasis, a place of relaxation and rest far away from the heat and the smothering of the narrow streets of the ksar.

The oasis is a place well comfortably adapted thanks to the vegetation and to the water which have been emphasized before previously and which must be remembered that they are not perceptible in the ksar. On the other hand, other unlucky families of ksar, in addition of their monotonous movements between ground floor, floor and terrace, they are enjoying their time with a "Guerba" or "Dellou". A traditional container of water, crafted from goat's skin, filled with water and hung at the entrance of the house on the ceiling to humidify the atmosphere of the house (ground floor) and to immediately refresh water and hot air in contact with the very small orifices of "Guerba".

The inhabitants of ksur settle at the oasis till the end of the harvesting of dates during the month of September.We notice, compared with our bioclimatic analysis, that this is great with the period previously determined that needs evaporative cooling (from June to September) to optimize comfort.

\section{Conclusions}

This present work is the result of a qualitative, descriptive analytical study and even a classification of the quasitotality of various traditional strategies of climate adaptation developed in Mzabite architecture to produce a real thermal comfort inside houses and a sensation of well-being of occupants. All the strategies, progressively, they are verified and certified the reality of their convergences or their divergences with the recommendations and the needs of own comfort to our case study and predetermined by Givoni method. Our analysis has shows clearly that the Mzabite architecture symbolizes an ancient bioclimatic expertise. It responds to the majority of recommendations and strategies announced and detailed in our bioclimatic analysis of Givoni. 
We are discussing today to preserve the urban heritage and integrating it masterfully into contemporary architecture. Indeed, the establishment of these strategies and precise planning in terms of climate in a respective urban, architectural and constructive really allows us to maintain, sustain and give a a new impetus to the skill and the great competency of former generation and their art to build, unfortunately, missing qualities in our days. These old ways are an inspiring reference and exemplary lesson model of a practical plan about environment; it will be a best sample available to designers acting in environments with hot and arid climates. However, it is a question of proposing a rereading and appropriate readjustment to the uses techniques of our time; today, we are facing with a degradation of natural resources, it is essential to put in value a new approach responding to the current requirements by adapting and using again these ancient solutions and techniques of our ancestors in a suitable manner in architecture of the modern times to grant a thermal comfort in our buildings without exceeded recourse to mechanical and artificial air conditioning of industry, and surely less costly electricity bills ,a moderate and limited use of energy produced that pollutes and nonrenewable, finally a clean environment to the generations coming up.

\section{References}

1. W.Sisson ,C.van-Aerschot , C.Kornevall, R.Cowe, D.Bridoux ,T.B.Bonnaire, J.Fritz , Eng Efficiency in Buildings: Transforming the Market. World Business Council for Sustainable Development (WBCSD), Switzerland (2009).

2. Ministère de l'Energie et des Mines. Agence Nationalepour la Promotion etla Rationalisation de l'Uti lisation de l'Energie (APRUE), Consommation Energétique Finale de l'Algérie. Chiffres clésAnnée2014,p.5(2012).

3. N .Vural, S .Vural, N.Engin, M.R .Sümerkan. Eastern Black Sea Region - a sample of modular design in the vernacular architecture. Build and Env, 42, pp.274661(2007).

4. C. Gallo, The utilization of microclimate elements, Renew and Sustainable Eng Rev, 2,pp.89-114(1998).

5. C.A. Roulet, Eco-confort - Pour une maison saine et à basse consommation d'énergie, Lausanne: PPUR, p.11 (2012).

6. I.Cañas, S.Martín, Recovery of Spanish vernacular construction as a model of bioclimatic architecture. Build and Env, 39,1477-1495(2004) .

7. G.Maniog, Z.Yilmaz, Energy efficient design strategies in the hot dry area of Turkey, Build and Env, 43 ,pp.1301-1309(2008) .

8. M.K.Singh, S.Mahapatra .S.K.Atreya , Bioclimatism and vernacular architecture of north-east India , Build and Env, p.44,878(2009).

9. C.Helena ,Bioclimatism in vernacular architecture, Renew and Sustainable Eng Rev ,2,pp.67-87(1998).

10. B.Cherifi, Etudes d'anthropologie historique et culturelle sur le M'zab, thèse sous la direction de Pierre Philippe Rey, Université de Paris VIII, 121 (2003).
11. C.Pavard, Lumieres Du M'Zab, Editions Delroisse, Boulogne-Billancourt , p.164, (1974).

12. B.Benyoucef, Le Mzab Parcours millénaire ,Éd.Alpha, Alger,p. 90(2010).

13. A. F .Toudert ,M.Djenane, R.Bensalem, H.Mayer, Outdoor thermal comfort in the old desert city of Beni-Izguen, Ghardaia, Algeria , Climt research , 28, pp.243-256 (2005).

14. A.Ravereau, Le M'Zab une leçon d'architecture, Éd. Actes Sud Sindbad, Arles ,p. 182 (1981).

15. S. Kitous ,R.Bensalema,L.Adolpheb, Airflow patterns within a complex urban topography under hot and dry climate in the Algerian, Build and Env, 56 , pp.162175(2012).

16. M.Mercier, La civilisation urbaine au Mzab, Ghardaïa la Mystérieuse,Éditions P \& G Soubiron, Alger,p. 146(1932).

17. I.Saito, O.Ishihara, T. Katayama, Study of the effect of green areas on the thermal environment in an urban area Eng and Build, 15, pp.443-446(1990).

18. OPVM (Office de Protection et de Promotion de la Vallée du M'Zab), Ghardaïa.

19. J.L.Izard, Soleil et architecture Contrôle d'ensoleillement par formes architecturales Techniques de l'ingénieur la lumière et l'isolation dans la construction (ref. article:c3311), p.33(2014).

20. S.Saljoughinejad, S.R.Sharifabad,Classification of climatic strategies, used in Iranian vernacular residences based on spatial constituent elements, Build and Env , 92,475-493(2015).

21. P.Supic, L'aspect bioclimatique de l'habitat vernaculaire, Trimestriel sci Archit \& Behav, 10, pp.27-47(1994).

22. B.Benyoucef, Le M'Zabespaceetsociété, Éd. IBD, Alger, p.136(1992).

23. Medjelakh.D, Abdou.S, Impact de l'inertiethermiquesur le conforthygrothermique et la consommationénergétique du bâtimen, Rev des EnergRen, 11,pp.329-341(2008).

24. A.Deherde, A, Liebard, Traitéd'architecture et d'urbanismebioclimatiques :Concevoir, édifier etaménager avec le développement durable, Éd. Moniteur, Paris, p.92(2005).

25. J.L.Izard,Architectures d'étéconstruire pour le confortd'été, Éd. Edisud, Aix-Province ,141p (1993).

26. C.Donnadieu Catherine, P. Didillon Henriette, M.Jean, Habiter le désert, les maisons mozabites, Éd. P. Mardaga, Bruxelles , 95 (1977). 